\title{
Physical activity and its association with body mass index among 10-15 years school children in Kalaburagi city, Karnataka, India
}

\author{
Mubeen Hussain*, Pallavi V. Tenglikar, S. R. Nigudgi
}

Department of Community Medicine, M. R. Medical College, Kalaburagi, Karnataka, India

Received: 30 June 2016

Accepted: 18 July 2016

\section{*Correspondence:}

Dr. Mubeen Hussain,

E-mail: mubeenhussain53@gmail.com

Copyright: (C) the author(s), publisher and licensee Medip Academy. This is an open-access article distributed under the terms of the Creative Commons Attribution Non-Commercial License, which permits unrestricted non-commercial use, distribution, and reproduction in any medium, provided the original work is properly cited.

\begin{abstract}
Background: Childhood obesity is a major public health problem, causing a significant morbidity and mortality. The objective of the present study was to identify certain associated risk factors for the prevalence of overweight and obesity among 10-15 years school children.

Methods: The present study was carried out in 1,642 school children aged between 10 to 15 years in Kalaburagi city of Karnataka. A predesigned and pretested questionnaire proforma was administered to each child to collect data on their physical activity level, T.V watching, duration of sleep, availability of playground etc. Parameters of height and weight were measured and recorded following completion of the questionnaire.

Results: The prevalence of overweight and obesity were more in those students who did not have accessibility of playground in-front of their houses (15.25\% and 8.47\%) and in those students travelling by Bus $(23.16 \%$ and $10.17 \%)$ and least in those students who reaches their school by walking $(8.52 \%$ and $3.85 \%)$. The prevalence of both overweight and obesity were more in those students who did not participated in any of the outdoor sports $(28.52 \%$ and $28.52 \%)$, who watched Television for more than 7 hours in a week $(14.25 \%$ and $8.73 \%)$ and in those students who slept for less than 6 hours a day $(8.75 \%)$.

Conclusions: Prevalence of overweight and obesity were high among the school children and need to be addressed by primary and secondary methods of prevention.
\end{abstract}

Keywords: Television, Outdoor sports, Playground, Overweight, Obesity

\section{INTRODUCTION}

The World Health Organization (WHO) stated that the growth in the number of severely overweight is expected to be double that of under-weight during 1995-2025 (WHO 1998). ${ }^{1}$ The prevalence of child obesity is increasing rapidly worldwide. It is associated with several risk factors for later heart disease and other chronic diseases including hyperlipidaemia, hyperinsulinaemia, hyper-tension, and early atherosclerosis. ${ }^{2}$

Childhood obesity and physical inactivity is increasing in both developing and developed countries although at different rates. ${ }^{3}$ The underlying plausible hypothesis in the development of obesity is that the feedback from energy expenditure to appetite may be weak at low levels of physical activity and that sedentary lifestyles therefore favour positive energy balance and weight gain. ${ }^{4}$

According to world health organization (WHO) a school aged youth should accumulate at least 60 minutes of moderate to vigorous intensity physical activity every day to ensure healthy development. It is estimated that less than one third of young people are sufficiently active to benefit their present and future health and wellbeing. This decline is largely due to increasingly common sedentary ways of life like fewer children walk or cycle to school and excessive time is devoted to watching television, 
playing computer games and other sedentary activities. School based physical activities have also been decreasing. ${ }^{5}$

Young children who do not get enough sleep are at increased risk of becoming overweight. ${ }^{6,7}$ The obesogenic environment encompasses the environmental features of modern lifestyles that are postulated to contribute to the increasing prevalence of obesity in particular, it is thought that the wide availability of food that is energy dense, palatable and inexpensive, combined with increasingly sedentary habits, favors an excess of energy intake over expenditure. $^{8}$

'Obesogenic schools' and Tution classes: An important factor for obesity in India is the intense competition for admissions to schools and colleges with flourishing tuition classes right from nursery levels Children are forced to use their play time for additional studies. Games or physical training sessions are restricted or nonexistent in many schools. Some schools do not have any playgrounds at all. Due to unsafe roads (traffic, crime) children are discouraged from walking or cycling to school. Motorized vehicles are popular and they are perceived to be quicker and safer for transport. Erosion of open spaces for exercise and lack of parental time to supervise play are all part of new obesogenic lifestyles. ${ }^{9}$ Hence it is very essential that the data on prevalence of obesity in school children and the factors responsible for obesity should be available to suggest interventional measures. Hence a modest attempt is been made in Kalaburagi city to find out the prevalence of overweight and obesity in School children aged between 10-15 years.

\section{Objectives}

To assess the various physical activities and its association with overweight and obesity in school children.

\section{METHODS}

A cross-sectional study was carried out to find out the various risk factors associated with overweight and obesity among 10-15 years school going children in Kalaburagi city, India. The present study was carried out in 1,642 school children aged between 10 to 15 years in Kalaburagi city (The prevalence of obesity was $5.74 \% .^{[10]}$ Hence $\mathrm{p}=5.74, \mathrm{q}=94.26$ and $\mathrm{L}=20 \%$ of $\mathrm{p}$, Sample size $\mathrm{n}$ $=4 \mathrm{pq} / \mathrm{l}^{2}$ where $\mathrm{n}=1,642$. In Kalaburagi city there are 212 schools having total children 29,715 aged between $10-15$ years.

Simple Random Sampling method is used, after selecting the schools randomly by lottery method. All children between 10-15 years in that school are included in the study, if the school population is less than the required sample; we select the second school by lottery method and repeat the process till the required sample is obtained. After selecting the school, prior consent from school authorities was obtained.

The students between 10- 15 years were interviewed personally with the help of oral questionnaire. A predesigned, pretested questionnaire proforma was administered to each child to collect data on their physical activity level, T.V watching, duration of sleep, availability of playground etc.

Parameters of height and weight were measured and recorded following completion of the questionnaire. In the entire programme the help of the teachers of the respective classes were taken. Repeated visits (up to 3) were done to the same school to examine those students who were absent at the previous visit. The statistical tests used are percentages and chi-square test. The statistical software SPSS-16 was used for the analysis of the data.

\section{RESULTS}

As Table 1 shows that the prevalence of overweight and obesity were more in those students who did not have accessibility of play groundinfront of their houses (15.25\% and $8.47 \%$ ) compared to those students who had play groundinfront of their houses $(11.43 \%$ and $5.37 \%)$. Hence availability of play groundinfront of their houses was highly significantly associated with overweight and obesity $(\mathrm{p}<0.001)$.

Table 1: Association between availability of playground and BMI.

\begin{tabular}{|llllllllll|l|l|}
\hline Play ground & Under weight & \multicolumn{3}{c}{ Normal weight } & \multicolumn{2}{c|}{ Over weight } & Obesity & Total \\
& No & \% & No & \% & No & \% & No & \% & No & \% \\
\hline No & 149 & 19.43 & 436 & 56.84 & 117 & 15.25 & 65 & 8.47 & 767 & 100.0 \\
\hline Yes & 239 & 27.31 & 489 & 55.89 & 100 & 11.43 & 47 & 5.37 & 875 & 100.0 \\
\hline Total & 388 & & 925 & & 217 & & 112 & 1642 & 100.0 \\
\hline
\end{tabular}

$\left(\chi^{2}=21.13\right.$, d.f $=3, p<0.001$ Highly significant $)$.

The Table 2 shows that the prevalence of overweight and obesity are more in those students travelling by Bus $(23.16 \%$ and $10.17 \%)$ followed by car $(19.35 \%$ and $25.81 \%$ ) and least in those students who reaches their school by walking $(8.52 \%$ and $3.85 \%)$ which are found to be statistically highly significant $(p<0.001)$. The prevalence of overweight and obesity is almost the same in those students who travelled to their schools by 
bicycle, motorcycle and rickshaw, which are found to be statistically not significant $(\mathrm{p}>0.05)$. The Table 3 shows that the prevalence of both overweight and obesity were more in those students who did not participated in any of the outdoor sports $(28.52 \%$ and $28.52 \%)$ which were found to be statistically highly significant $(\mathrm{p}<0.001)$.

Table 2: Association between use of mode of transport to school and BMI.

\begin{tabular}{|c|c|c|c|c|c|c|c|c|c|c|c|c|c|c|c|c|}
\hline \multirow{3}{*}{ Transport } & \multicolumn{4}{|c|}{ Underweight (388) } & \multicolumn{4}{|c|}{ Normal Weight (925) } & \multicolumn{4}{|c|}{ Overweight (217) } & \multicolumn{4}{|c|}{ Obesity (112) } \\
\hline & Yes & & No & & Yes & & No & & Yes & & No & & Yes & & No & \\
\hline & No & $\%$ & No & $\%$ & No & $\%$ & No & $\%$ & No & $\%$ & No & $\%$ & No & $\%$ & No & $\%$ \\
\hline Bus & 22 & 12.43 & 366 & 24.98 & 96 & 54.24 & 829 & 56.59 & 41 & 23.16 & 176 & 12.01 & 18 & 10.17 & 94 & 6.42 \\
\hline Car & 3 & 9.68 & 385 & 23.90 & 14 & 45.16 & 911 & 56.55 & 6 & 19.35 & 211 & 13.10 & 8 & 25.81 & 104 & 6.46 \\
\hline Bicycle & 116 & 27.55 & 272 & 22.28 & 223 & 52.97 & 702 & 57.49 & 52 & 12.35 & 165 & 13.51 & 30 & 7.13 & 82 & 6.72 \\
\hline Motorcycle & 24 & 19.83 & 364 & 23.93 & 67 & 55.37 & 858 & 56.41 & 22 & 18.18 & 195 & 12.82 & 8 & 6.61 & 104 & 6.84 \\
\hline Rickshaw & 85 & 21.30 & 303 & 24.38 & 231 & 57.89 & 694 & 55.83 & 54 & 13.53 & 163 & 13.11 & 29 & 7.27 & 83 & 6.68 \\
\hline Walking & 138 & 27.99 & 250 & 21.76 & 294 & 59.63 & 631 & 54.92 & 42 & 8.52 & 175 & 15.23 & 19 & 3.85 & 93 & 8.09 \\
\hline
\end{tabular}

Table 3: Association between participation in outdoor sports and BMI.

\begin{tabular}{|c|c|c|c|c|c|c|c|c|c|c|}
\hline \multirow[t]{2}{*}{ Outdoor sports } & \multicolumn{2}{|c|}{ Under weight } & \multicolumn{2}{|c|}{ Normal weight } & \multicolumn{2}{|c|}{ Over weight } & \multicolumn{2}{|c|}{ Obesity } & \multicolumn{2}{|c|}{ Total } \\
\hline & No & $\%$ & No & $\%$ & No & $\%$ & No & $\%$ & No & $\%$ \\
\hline No & 26 & 9.89 & 87 & 33.08 & 75 & 28.52 & 75 & 28.52 & 263 & 100.0 \\
\hline$<4$ hours/week & 238 & 25.11 & 579 & 61.08 & 107 & 11.29 & 24 & 2.53 & 948 & 100.0 \\
\hline 4-7 hours/week & 113 & 29.27 & 231 & 59.84 & 31 & 8.03 & 11 & 2.85 & 386 & 100.0 \\
\hline$>7$ hours/week & 11 & 24.44 & 28 & 62.22 & 4 & 8.89 & 2 & 4.44 & 45 & 100.0 \\
\hline Total & 388 & & 925 & & 217 & & 112 & & 1642 & 100.0 \\
\hline
\end{tabular}

$\left(\chi^{2}=331.39\right.$, D.F $=9, \mathrm{P}<0.001$ highly significant $)$.

Table 4: Association between participation in Indoor sports and BMI.

\begin{tabular}{|c|c|c|c|c|c|c|c|c|c|c|}
\hline \multirow{2}{*}{ Indoor sports } & \multicolumn{2}{|c|}{ Under weight } & \multicolumn{2}{|c|}{ Normal weight } & \multicolumn{2}{|c|}{ Over weight } & \multicolumn{2}{|c|}{ Obesity } & \multicolumn{2}{|c|}{ Total } \\
\hline & No & $\%$ & No & $\%$ & No & $\%$ & No & $\%$ & No & $\%$ \\
\hline No & 40 & 27.40 & 84 & 57.53 & 16 & 10.96 & 6 & 4.11 & 146 & 100.00 \\
\hline$<4$ hours/week & 281 & 24.18 & 658 & 56.63 & 146 & 12.56 & 77 & 6.63 & 1162 & 100.00 \\
\hline 4-7 hours/week & 65 & 22.41 & 159 & 54.83 & 42 & 14.48 & 24 & 8.28 & 290 & 100.00 \\
\hline$>7$ hours/week & 2 & 4.55 & 24 & 54.55 & 13 & 29.55 & 5 & 11.36 & 44 & 100.00 \\
\hline Total & 388 & & 925 & & 217 & & 112 & & 1642 & \\
\hline
\end{tabular}

$\left(\chi^{2}=22.22\right.$, d.f $=9, \mathrm{p}<0.01 \quad$ Significant $)$.

Table 5: Association between participation in physical activity and BMI.

\begin{tabular}{|c|c|c|c|c|c|c|c|c|c|c|}
\hline \multirow[t]{2}{*}{ Physical activity } & \multicolumn{2}{|c|}{ Under weight } & \multicolumn{2}{|c|}{ Normal weight } & \multicolumn{2}{|c|}{ Over weight } & \multicolumn{2}{|c|}{ Obesity } & \multicolumn{2}{|c|}{ Total } \\
\hline & No & $\%$ & No & $\%$ & No & $\%$ & No & $\%$ & No & $\%$ \\
\hline No & 23 & 8.88 & 85 & 32.82 & 74 & 28.57 & 77 & 29.73 & 259 & 100.0 \\
\hline$<4$ hours/week & 272 & 25.54 & 656 & 61.6 & 110 & 10.33 & 27 & 2.54 & 1065 & 100.0 \\
\hline 4-7 hours/week & 84 & 30.77 & 155 & 56.78 & 27 & 9.89 & 7 & 2.56 & 273 & 100.0 \\
\hline$>7$ hours/week & 9 & 20 & 29 & 64.44 & 6 & 13.33 & 1 & 2.22 & 45 & 100.0 \\
\hline Total & 388 & & 925 & & 217 & & 112 & & 1642 & 100.0 \\
\hline
\end{tabular}

$\left(\chi^{2}=354.64\right.$, D.F $=9, \mathrm{P}<0.001$ highly significant $)$.

Table 6: Association between T.V. watching and BMI.

\begin{tabular}{|lllllllllll|}
\hline \multirow{2}{*}{ TV watching } & \multicolumn{2}{l}{ Under weight } & \multicolumn{2}{c}{ Normal weight } & \multicolumn{2}{c|}{ Over weight } & Obesity & \multicolumn{2}{c|}{ Total } \\
& No & $\mathbf{\%}$ & No & $\mathbf{\%}$ & No & $\mathbf{\%}$ & No & \% & No & \% \\
\hline No & 25 & 30.49 & 45 & 54.88 & 9 & 10.98 & 3 & 3.66 & 82 & 100.00 \\
\hline$<7$ hours/week & 195 & 24.97 & 448 & 57.36 & 97 & 12.42 & 41 & 5.25 & 781 & 100.00 \\
\hline$>7$ hours/week & 168 & 21.57 & 432 & 55.46 & 111 & 14.25 & 68 & 8.73 & 779 & 100.00 \\
\hline Total & 388 & & 925 & & 217 & & 112 & & 1642 & 100.00 \\
\hline
\end{tabular}

$\left(\chi^{2}=13.41\right.$, d.f $=6, p<0.05$ Significant $)$. 
Table 7: Association between duration of sleep and BMI.

\begin{tabular}{|c|c|c|c|c|c|c|c|c|c|c|}
\hline \multirow[t]{2}{*}{ Duration of sleep } & \multicolumn{2}{|c|}{ Under weight } & \multicolumn{2}{|c|}{ Normal weight } & \multicolumn{2}{|c|}{ Over weight } & \multicolumn{2}{|c|}{ Obesity } & \multicolumn{2}{|l|}{ Total } \\
\hline & No & $\%$ & No & $\%$ & No & $\%$ & No & $\%$ & No & $\%$ \\
\hline Less than 6 hours/day & 98 & 23.17 & 252 & 59.57 & 36 & 8.51 & 37 & 8.75 & 423 & 100.0 \\
\hline 6-8 hours/day & 248 & 23.35 & 594 & 55.93 & 156 & 14.69 & 64 & 6.03 & 1062 & 100.0 \\
\hline More than 8 hours/day & 42 & 26.75 & 79 & 50.32 & 25 & 15.92 & 11 & 7.01 & 157 & 100.0 \\
\hline Total & 388 & & 925 & & 217 & & 112 & & 1642 & 100.0 \\
\hline
\end{tabular}

$\left(\chi^{2}=15.54\right.$, D.F $=6, P<0.05$ significant $)$.

The table 4 shows that the prevalence of both overweight and obesity were maximum in those students who played sedentary indoor games for more than 7 hours in a week $(29.55 \%$ and $11.36 \%)$ compared to those students who did not played any of the sedentary Indoor games $(10.96 \%$ and $4.11 \%)$.

Hence participation in indoor sports was significantly associated with overweight and obesity $(p<0.01)$. The table 5 shows that the prevalence of both overweight and obesity were more among those students who did not participated in any of the physical activities $(28.57 \%$ and $29.73 \%$ ). Which were found to be statistically highly significant $(\mathrm{p}<0.001)$. The table 6 shows that the prevalence of overweight and obesity was more in those students who watched Television for more than 7 hours in a week (14.25\% and $8.73 \%$ ) followed by those watching less than 7 hours a week $(12.42 \%$ and $5.25 \%)$ respectively. Hence watching T.V was significantly associated with overweight and obesity $(\mathrm{p}<0.05)$.

The table 7 reveals that overweight was more in those students who slept for more than 8 hours in a day $(15.92 \%)$ followed by 6- 8hours/day (14.69\%) and less than 6 hours/day $(8.51 \%)$. But the prevalence of obesity was more in those students who slept for less than 6 hours a day $(8.75 \%)$ followed by more than 8 hours/day $(7.01 \%)$. Duration of sleep/day was significantly associated with overweight and obesity $(\mathrm{p}<0.05)$.

\section{DISCUSSION}

The present epidemiological cross-sectional study was carried out in both Government and Private schools of Kalaburagi city, India. This study consisted of 1642 students between ages 10-15 years, were undertaken to know certain associated risk factors of overweight and obesity. The present study showed that the prevalence of overweight and obesity were more in those students who did not have accessibility of play ground in front of their houses $(15.25 \%$ and $8.47 \%$ ) compared to those students who had play ground in front of their houses $(11.43 \%$ and $5.37 \%)$.

A study done by Shylesh R et al among 11-15 year school children in Coimbatore in the year 2011 reveled that location of home in a non-residential area and main roads, absence of playground nearby homes had a high prevalence of both overweight and obesity. ${ }^{5}$ The present study revealed that the prevalence of overweight and obesity was more in those students travelling by bus $(23.16 \%$ and $10.17 \%)$ followed by car $(19.35 \%$ and $25.81 \%$ ) and least in those students who reaches their school by walking $(8.52 \%$ and $3.85 \%)$.

A study done by Shylesh R et al among 11-15 year school children in Coimbatore in the year 2011 reveled that those who travelled to their school by motor vehicle had a high percentage of obesity. ${ }^{5}$

The present study shows that the prevalence of both overweight and obesity were more in those students who did not participated in any of the outdoor sports $(28.52 \%$ and $28.52 \%$ ). A study done by Goyal RK et al among adolescent school children aged 12-18 years in Ahmedabad in the year 2010 revealed that physical activity like outdoor sports have a remarkable effect on prevalence of overweight and obesity. ${ }^{11}$

In a study done by Bharati et al among school going children in Wardha city in the year 2008 showed that from a multivariate logistic regression that one of the important co-relates of overweight/ obesity was child playing outdoor sports for less than 30 minutes a day. ${ }^{12}$ Similar findings were also noted by a study done by $\mathrm{M}$ Shashidhar et al among 12-15 years adolescent in Mangalore in the year 2010 showed that from a multivariate logistic regression that the prevalence of overweight and obesity was 21 times higher among those participant engaged in less than two hours/week in any type of physical activity. ${ }^{13}$

The present study showed that the prevalence of both overweight and obesity were maximum in those students who played sedentary indoor games and least in those students who did not played any of the sedentary indoor games. A study done by M Shashidhar et al among 12-15 years adolescent in Mangalore in the year 2010 showed that from a multivariate logistic regression that the prevalence of overweight and Obesity was 7.3 times higher in those who participated in playing games on the computer for more than 4 hours a day. ${ }^{13}$

The present study reveals that the prevalence of both overweight and obesity were more among those students 
who did not participated in any of the physical activities. A study done by Goyal RK et al on adolescent school children aged 12-18 years in Ahmadabad in the year 2010 revealed that those students with reduced physical activities like exercise have remarkable effect on the prevalence of overweight and obesity. ${ }^{11}$ Similarily a study done by Shylesh R et al among 11-15 year school children in Coimbatore in the year 2011 revealed that $20.5 \%$ of obese children had inadequate physical activities. $^{5}$

A study done by Ibrahim et al among adolescent aged 1014 years in Kuwait in the year 2006 revealed that the prevalence of overweight and Obesity was $30.7 \%$ and $14.6 \%$ respectively and majority of them reported physical inactivity. ${ }^{14}$ Similarly a study done by $\mathrm{M}$ Shashidhar et al among 12-15 years adolescent in Mangalore in the year 2010. ${ }^{13}$ A multivariate logistic regression revealed that the prevalence of overweight and obesity was 21 times higher among those participating less than two hours in a week in any type of physical activity.

The present study shows that the prevalence of overweight and Obesity was more in those students who watched Television for more than 7 hours in a week $(14.25 \%$ and $8.73 \%)$ followed by those watching less than 7 hours a week $(12.42 \%$ and $5.25 \%)$. In a study done by shabana $\mathrm{T}$ et al among 8-15 year school children in Chennai in the year 2009 revealed that the prevalence of overweight and Obesity was greater in children watching television more than 2 hours (OR -2.5 , CI-1.1 to 5.4, $\mathrm{p}<0.0001) .{ }^{15}$

Similarily in a study done by Vioque $\mathrm{J}$ et al in Spain in the year 2000 reveales that obese people reported to spend more time watching T.V (mean \pm s.d.: $3.6 \pm 1.5$ $\mathrm{h} /$ day) than non-obese ones $(3.0 \pm 1.4 \mathrm{~h} /$ day $) .{ }^{16}$ In multivariate analysis, obesity was associated with TV viewing, sleeping time and physical activity at work. People watching TV $\geq 4 \mathrm{~h} /$ day showed a higher adjusted prevalence odds ratio of obesity, $\mathrm{POR}=2.38(95 \%$ confidence interval, 1.54-3. 691, compared with those watching $\mathrm{TV} \leq 1 \mathrm{~h} /$ day. A study done by Khader $\mathrm{Y}$ et al among school children aged between 6-12 years in Jordan in the year 2009 reveals that watching Television for $>2$ hours/day were significantly associated with increased odds of both overweight and obesity. ${ }^{17}$

The present study reveals that overweight was more in those students who slept for more than 8 hours in a day $(15.92 \%)$ followed by 6- 8hours/day (14.69\%) and less than 6 hours/day $(8.51 \%)$. But the prevalence of obesity was more in those students who slept for less than 6 hours a day $(8.75 \%)$ followed by more than 8 hours/day $(7.01 \%)$.

Whereas a study done by Philippa J C et al among children aged 3-7 years in New Zealand in the year 2011 revealed that young children who do not get enough sleep are at increased risk of becoming overweight. ${ }^{6}$ Similarly in a study done by Vioque $J$ et al in Spain in the year 2000 reveals that people who reported to sleep $\geq 9 \mathrm{~h} /$ day presented a lower POR of obesity than those sleeping $\leq 6$ $\mathrm{h} /$ day, POR $=0.43(0.27-0.67) .{ }^{16}$ Statistically significant dose-responses were observed, so that the prevalence odds ratio of obesity was $24 \%$ lower for each additional hour of sleeping time.

\section{CONCLUSION}

Primary prevention is possible by modifying obesogenic environmental factors such as increased physical activity, dietary modification, behavioral changes etc. Long term studies have shown beneficial effects of life style modifications on reducing the risk of obesity. India is going to face big challenge posed by the rising prevalence of obesity and its future complication unless steps are taken to implement the primary prevention of obesity.

Funding: No funding sources

Conflict of interest: None declared

Ethical approval: The study was approved by the Institutional Ethics Committee

\section{REFERENCES}

1. Agrawal PK. "Emerging Obesity in Northern Indian States: A Serious threat for Health" (PDF). IUSSP Conference, Bankik. 2002;23:10-2.

2. Cole TJ, Bellizzi MC, Flegal KM, Dietz WH. Establishing a standard definition for child overweight and obesity worldwide: international survey. British Medical Journal. 2000;320:1240-43.

3. Vincent O. Onywera. Childhood obesity and physical inactivity threat in Africa: strategies for a healthy future. Global Health Promotion. 2010;17:45.

4. Ferro-Luzzi A, Martino L. Obesity and physical activity. Ciba Foundation Symposium 201 - The Origins and Consequences of Obesity. 2007 DOI: 10.1002/9780470514962.ch13.

5. Shylesh R, Suvetha K. A study on obesity and factors influencing physical activity among adolescents aged 11- 15years in urban school of Coimbatore. Asian Student Medical Journal. 2011;7:4.

6. Carter PJ, Taylor BJ, Williams SM, Taylor RW. Longitudinal analysis of sleep in relation to BMI and body fat in children: The FLAME study. British Medical Journal. 2011;342:2712.

7. Riddoch CJ, Leary SD, Ness AR, Blair SN, Deere $\mathrm{K}$, Mattocks C, et al. Prospective associations between objective measures of physical activity and fat mass in 12-14 year old children: the Avon Longitudinal Study of Parents and Children (ALSPAC). BMJ. 2009;339:4544.

8. Chaput JP. A study on modern sedentary activities promote overconsumption of food in our current 
obesogenic environment. Obes Rev 12:12-20. PMID 20576006.

9. Bhave S, Bavdekar A, Otiv M. IAP national task force for childhood prevention of adult diseases: childhood obesity. Indian Pediatrics. 2004;41:55975.

10. Kumar S, Mahabalaraju DK, Anuroopa MS. A study on prevalence of obesity and its influencing factors among affluent school children of Davangere city. IJCM 2007;32(1): 15-7.

11. Goyal RK, Shah VN, Saboo BD, Phatak SR, Shah NN, Gohel MC, et al. Prevalence of overweight and obesity in Indian adolescent school going children: its relationship with socioeconomic status and associated lifestyle factors. J Assoc Physicians India. 2010;58:151-8.

12. Bharati DR, Deshmukh PR, Garg BS. Correlates of overweight \& obesity among school going children of Wardha city, Central India.Indian J Med Res. 2008;127(6):539-43.

13. Kotian MS, Kumar GS, Kotian SS. A study on prevalence and determinants of overweight and obesity among adolescent school children of South Karnataka, India. Indian J Community Med. 2010;35(1):176-8.
14. Ibrahim El-Bayoumy, Ibrahim Shady and HeshamLotfy. A study on prevalence of obesity among adolescents (10 to 14 Years) in Kuwait. Asian pacific journal of public health 2009;21:1539.

15. Tharkar S, Viswanathan V. A study on impact of Socioeconomic Status on Prevalence of Overweight and Obesity among Children and Adolescents in Urban India. The Open Obesity Journal. 2009;(1):914.

16. Vioque J, Torres A, Quiles J. Time spent watching television, sleeps duration and obesity in adults living in Valencia, Spain. International journal of obesity. 2000;24(12):1683-88.

17. Khader Y, Irshaidat O, Khasawneh M, Amarin Z, Alomari M, Batieha A. A study onoverweight and obesity among school children in Jordan: prevalence and associated factors. Maternal Child Health J. 2009;13(3):424-31.

Cite this article as: Hussain M, Tenglikar PV.

Nigudgi SR. Physical activity and its association with body mass index among 10-15 years school children in Kalaburagi city, Karnataka, India. Int J Community Med Public Health 2016;3:2264-9. 